\title{
14-3-3 proteins are essential signalling hubs for beta cell survival
}

\author{
G. E. Lim • M. Piske • J. D. Johnson
}

Received: 16 August 2012 / Accepted: 11 December 2012 / Published online: 26 January 2013

(C) Springer-Verlag Berlin Heidelberg 2013

\begin{abstract}
Aims/hypothesis Diabetes is characterised by pancreatic beta cell death and dysfunction, resulting from unbalanced pro-survival and pro-death signalling. The 14-3-3 proteins are molecular adaptors that integrate numerous signalling pathways, including the v-raf-leukaemia viral oncogene 1 (RAF1)/B cell leukaemia/lymphoma 2 (BCL-2)-associated agonist of cell death (BAD) pathway, which we have previously implicated in insulin-dependent beta cell survival. Nevertheless, the roles of 14-3-3 proteins in beta cell fate and function have not been investigated.

Methods We examined the abundance, localisation, modulation and roles of 14-3-3 proteins using quantitative RTPCR, immunoblot or imaging. MIN6 cells or mouse islets cells were manipulated with inhibitors, short interfering RNA (siRNA) or plasmids overexpressing 14-3-3.

Results We first characterised the abundance and subcellular location of all seven 14-3-3 isoforms in mouse and human beta cells. Most isoforms were cytoplasmic, except 14-3-3 $\sigma$, which appeared to be nuclear. Analysis of 14-3-3 abundance under stress conditions revealed distinct modulation in mouse islets and MIN6 cells. Generalised 14-3-3 inhibition promoted apoptosis and dysfunction, and siRNAmediated knockdown revealed isoform-specific roles in
\end{abstract}

Electronic supplementary material The online version of this article (doi:10.1007/s00125-012-2820-x) contains peer-reviewed but unedited supplementary material, which is available to authorised users.

G. E. Lim $•$ M. Piske $\cdot$ J. D. Johnson $(\bowtie)$

Diabetes Research Group, Department of Cellular and

Physiological Sciences, University of British Columbia,

5358 Life Sciences Building, 2350 Health Sciences Mall,

Vancouver, BC, Canada V6T 1 Z3

e-mail: James.D.Johnson@ubc.ca

J. D. Johnson

Department of Surgery, University of British Columbia,

Vancouver, BC, Canada caspase-3-dependent beta cell apoptosis, with a clear role

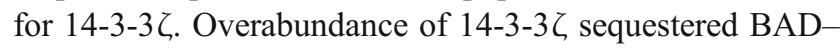
BCL2-associated X protein (BAX) from mitochondria, attenuated $D p 5$ (also known as Hrk) and Puma (also known as $B b c 3$ ) induction, and increased survival in response to proinflammatory cytokines or thapsigargin. Anti-apoptotic insulin treatment increased the sequestration of $\mathrm{BAD} / \mathrm{BAX}$ by

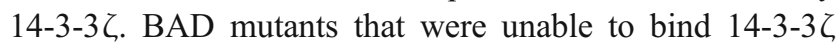
localised to mitochondria and induced apoptosis.

Conclusions/interpretation This first study of the 14-3-3 family in beta cells revealed specific regulation, localisation and anti-apoptotic roles among the isoforms. Focus on 14-3$3 \zeta$ revealed its importance in preventing BAD-BAX mitochondrial localisation and protecting beta cells from multiple stresses. Thus, some 14-3-3 proteins are pro-survival signalling hubs.

Keywords $14-3-3 \zeta \cdot \mathrm{BAD} \cdot \mathrm{BAX} \cdot$ Insulin signalling · Mitochondria $\cdot$ Molecular adaptors

$\begin{array}{ll}\text { Abbreviations } \\ \text { ASK1 } & \text { Apoptosis signal-regulated kinase-1 } \\ \text { BAD } & \text { BCL2-associated agonist of cell death } \\ \text { BAX } & \text { BCL2-associated X protein } \\ \text { BCL-2 } & \text { B cell leukaemia/lymphoma 2 } \\ \text { Bclx }_{\text {L }} & \text { B-cell lymphoma-extra large } \\ \text { BH3 } & \text { Bcl-2 homology domain } 3 \\ \text { CHOP } & \text { CCAAT/-enhancer-binding protein } \\ & \text { homologous protein } \\ \text { COX-IV } & \text { Cytochrome c oxidase subunit IV } \\ \text { dsRed } & \text { Red fluorescent protein from Discosoma } \text { coral } \\ \text { ER } & \text { Endoplasmic reticulum } \\ \text { ERK } & \text { Extracellular signal-related kinase } \\ \text { GFP } & \text { Green fluorescent protein } \\ \text { HA } & \text { Haemagglutinin } \\ \text { JNK } & \text { c-Jun N-terminal kinase } \\ \text { mRFP } & \text { Monomeric red fluorescent protein }\end{array}$


NF $\kappa$ B Nuclear factor $\kappa B$

RAF1 V-Raf-leukaemia viral oncogene 1

SAPK Stress-activated protein kinase

siRNA Short interfering RNA

YFP Yellow fluorescent protein

\section{Introduction}

The causes of diabetes are complex, with multiple factors contributing to the death and dysfunction of pancreatic beta cells $[1,2]$. Despite recent advances in elucidating the mechanisms underlying beta cell death, attempts to prevent the onset of diabetes have been unsuccessful. Numerous hormones promote cell survival, but it is not understood how their downstream signalling pathways are coordinated. Molecular adaptor proteins are key factors that facilitate and integrate multiple signalling cues by recognising specific proteins based on their post-translational modifications. These adaptors coordinate the cellular localisation of specific proteins, leading to the accurate transduction of multiple parallel signals [3]. The roles of such adaptor proteins remain largely unexplored in beta cells.

The seven members of the mammalian 14-3-3 protein family are molecular adaptors that recognise proteins bearing phospho-serine or phospho-threonine motifs [4]. 14-3-3 dimers simultaneously bind multiple proteins and coordinate their orientation and activity [5]. All 14-3-3 proteins have a similar structure, but the extent to which they have evolved distinct roles remains unclear [6]. Evidence from lower organisms and mammalian cell lines shows specific and overlapping roles of each isoform [7, 8]. However, a thorough side-by-side comparison of each endogenous isoform has yet to be performed in any endocrine cell type. Studies have demonstrated the involvement of 14-3-3 proteins in many cellular functions, including positive and negative roles in programmed cell death through their effects on protein stability and protein localisation [4, 9-11]. To mediate cell survival, 14-3-3 isoforms bind to and inhibit the pro-apoptotic activity of B cell leukaemia/ lymphoma 2 (BCL2)-associated agonist of cell death (BAD), following its phosphorylation by v-raf-leukaemia viral oncogene 1 (RAF1) or Akt [10, 12]. Of the seven isoforms, $14-3-3 \zeta$ is known to modulate the activity of RAF1 [13], which can regulate the production and activity of BAD in beta cells [14-17]. It remains to be determined whether $14-3-3 \zeta$ is critical in the regulation of cell survival. The above evidence suggests that 14-3-3 proteins serve as unique integration points to coordinate kinase activity and phospho-dependent survival cues [18]. Therefore, we tested the hypothesis that 14-3-3 proteins are essential for coordinating beta cell survival as the core of a signalling node that integrates multiple survival signals.
We report the first side-by-side comparison of all 14-3-3 isoforms in any endocrine cell type and identified a critical anti-apoptotic role for $14-3-3 \zeta$. These findings suggest that increasing 14-3-3 $\zeta$ levels or activity could be a novel approach to the prevention of beta cell death that occurs in diabetes.

\section{Methods}

Cell culture, transient transfection and reagents MIN6 cells were cultured as described [14]. Experiments were repeated across multiple passages (28 to 45 ). Mouse islets were isolated from C57/BL6 mice and purified by filtration [15]. Islets were maintained in $10 \mathrm{mmol} / 1$ glucose RPMI with $10 \%$ FBS (vol./vol.) and penicillin/streptomycin. Human islets (60-80\% pure) were collected by G. Warnock (Vancouver General Hospital, Vancouver, BC, Canada) with informed consent from donors, who were 40 to 60 years of age and had no history of diabetes. All mouse islet protocols were performed in accordance with guidelines of the University of British Columbia Animal Care committee. Studies with human islets had institutional review board approval and followed principles from the Declaration of Helsinki of 2000.

MIN6 cells were transfected with commercially available short interfering RNA (siRNA) against each 14-3-3 isoform using Lipofectamine 2000 (Life Technologies, Burlington, ON, Canada). A scrambled, non-targeting siRNA served as the negative control. All experiments were performed $48 \mathrm{~h}$ after transfection. MIN6 cells and mouse islets were electroporated (Neon System; Life Technologies) to deliver plasmids encoding: (1) difopein-yellow fluorescent protein (YFP) (gift from H. Fu, Emory University); (2) Haemagglutinin (HA)-14-3-3 C (gift from A. Muslin, Washington University in St Louis); (3) green fluorescent protein (GFP)-14-3-3 (Genecopeia, Rockville, MD, USA); (4) BAD-GFP mutants (gift from A. Tolkovsky, University of Cambridge); (5) mitochondria-targeted dsRed (from $\mathrm{H}$. McBride, University of Ottawa); or (6) their respective control plasmids.

In studies examining the response to insulin (SigmaAldrich, St Louis, MO, USA), MIN6 cells were starved overnight with $5 \mathrm{mmol} / 1$ glucose DMEM with $0.5 \% \mathrm{FBS}$ (vol./vol.), followed by $2 \mathrm{~h}$ incubation in $0 \mathrm{mmol} / 1$ glucose KRB supplemented with $0.2 \%$ BSA (wt/vol.). The 14-3-3 antagonist, I 2-5, was from EMD/Millipore (Billerica, MA, USA). Cytokines (25 ng/ml TNF $\alpha, 10$ ng/ml IL- $1 \beta, 10$ ng/ml IFN- $\gamma$ ) were from R\&D Systems (Minneapolis, MN, USA). Thapsigargin $(1 \mu \mathrm{mol} / \mathrm{l})$ and anisomycin $(1 \mu \mathrm{mol} / \mathrm{l})$ were from Sigma (St Louis, MO, USA).

Quantitative real-time PCR and gene analysis RNA was isolated from MIN6 cells or islets using a kit (RNeasy; 
Qiagen, Mississauga, ON, Canada). cDNA was generated with a kit (qScript cDNA Synthesis; Quanta Biosciences, Gaithersburg, MD, USA) and transcript levels were measured with SYBR Green fluorescence (StepOnePlus Real-Time PCR System; Applied Biosystems, Carlsbad, CA, USA). All quantitative PCR data were normalised to Hprt via the $2^{-\Delta \mathrm{C}_{\mathrm{t}}}$ method; expression of Hprt was not changed under any experimental conditions. Mature mouse or human beta cells were identified after infection with a $P d x 1$-mRFP-Ins 1-eGFP dual reporter lentivirus and fluorescence-activated cell sorting using a Cytopeia Influx device (BD Biosciences, San Jose, CA, USA) [19, 20]. The relative levels of each 14-3-3 isoform were collected from gene array data (Illumina MouseWG-6 version 2.0 Expression BeadChip, Illumina, San Diego, CA, USA). Other observations from that gene array experiment have been published [20].

Insulin secretion analysis MIN6 cells or dispersed mouse islets were pre-incubated for $2 \mathrm{~h}$ in $0 \mathrm{mmol} / 1$ glucose KRB with $0.2 \%$ BSA (wt/vol.). Cells were subsequently washed with PBS and incubated for $2 \mathrm{~h}$ in 3 or $16 \mathrm{mmol} / \mathrm{l}$ glucose made with KRB-BSA. The medium was collected and centrifuged at $900 \mathrm{~g}(3,000 \mathrm{rpm})$. Secreted insulin in supernatant fractions and insulin content in cell lysates were measured by radioimmunoassay (Millipore). Secretion data were normalised to total islet protein.

Western blot and immunoprecipitation MIN6 cells were washed with PBS prior to lysis with RIPA buffer, supplemented with protease inhibitors (Roche Applied Sciences, Laval, QC, Canada). Immunoprecipitation experiments were performed as previously described [15]. Pull-down of HA-14-3-3 $\zeta$ was performed with anti-HA-conjugated agarose beads (Sigma-Aldrich). Cytoplasmic and mitochondrial fractions were separated from crude cell lysates with a kit (Mitochondria/Cytosol Fractionation Kit; Biovision, Mountain View, CA, USA). Proteins were resolved by SDSPAGE, transferred to polyvinylidene difluoride membranes and probed with antibodies against: cleaved caspase-3, pSer112 BAD, pSer136 BAD, BAD, BCL2-associated X protein (BAX), cytochrome c oxidase subunit IV (COX-IV), pAkt (Ser473), Akt, p-extracellular signal-related kinase (ERK)1/2 (Thr202/Tyr 204), p-c-Jun N-terminal kinase (JNK) $1 / 2$, JNK1/2, 14-3-3 $\beta, 14-3-3 \gamma, 14-3-3 \varepsilon, 14-3-3 \zeta$, $14-3-3 \eta$ and $14-3-3 \theta$ (all from Cell Signaling Technology, Danvers, MA, USA); and 14-3-3 $\sigma$ (Millipore); $\beta$-actin (Novus Biologicals, Littleton, CO, USA); HA (Santa Cruz Biotechnology, Santa Cruz, CA, USA); CHOP (Millipore); and $\beta$-tubulin (Sigma-Aldrich).

Fluorescent imaging Mouse pancreatic sections from C57/ BL6 mice were de-paraffinised, rehydrated, subjected to sodium citrate antigen retrieval, incubated in serum-free protein block (DAKO, Burlington, ON, Canada) and incubated overnight with antibodies against 14-3-3 isoforms (Cell Signaling Technology and Millipore) and insulin (Sigma-Aldrich), followed by Alexafluor-conjugated secondary antibodies (Life Technologies). Dispersed islets or MIN6 cells were seeded on glass coverslips or in 96-well plates. All images were taken with identical exposure times using an inverted microscope (200M; Zeiss, Toronto, ON, Canada) and deconvolved with SlideBook software (Intelligent Imaging Innovations, Denver, CO, USA). Some images were obtained with an inverted confocal microscope (FluoView FV1000 Laser Scanning, Olympus, Markham, ON, Canada). Live-cell analysis of cell death was measured in MIN6 cells or dispersed mouse islets incubated in $25 \mathrm{mmol} / 1$ glucose DMEM or $10 \mathrm{mmol} / 1$ glucose RPMI, respectively, which contained propidium iodide and Hoechst 33342. Dying cells (positive for propidium iodide and Hoechst 33342) were determined from the total number of cells counted from 30 fields in a well from a 96well plate, using a live-cell imager (ImageXpress ${ }^{\text {MICRO; }}$ Molecular Devices, Sunnyvale, CA, USA); quantification was done with a software package (MetaXpress; Molecular Devices). A $\times 10$ objective was used to capture a large number of cells. However, a disadvantage of this high-throughput approach is that the type of cell death could not be discerned by nuclear morphology (Hoechst 33342).

Statistical analysis Data are expressed as mean \pm SEM and were analysed by Student's $t$ test or ANOVA, followed by post-hoc analysis where appropriate. Results were considered statistically significant at $p<0.05$.

\section{Results}

14-3-3 isoforms in pancreatic beta cells To date, no published study has compared the roles of all 14-3-3 isoforms. As a first step, using quantitative PCR, we found that all 143-3 isoforms are present in isolated mouse islets and in MIN6 cells (Fig. 1a, b), with similar results found in gene array analysis of FACS-purified mouse and human beta cells [20] (Fig. 1c, d). The localisation of each 14-3-3 protein was characterised in beta cells (Fig. 1e). The 14-3-3 $\sigma$ isoform was predominantly localised to the nucleus, whereas the $\gamma$ and $\zeta$ isoforms were distributed between the cytosol and nucleus; the remaining isoforms were cytoplasmic. The 143-3 group of proteins exists as homo- or heterodimers, which influences their repertoire of binding partners [5]. As expected, co-immunoprecipitation of 14-3-3 $\zeta$ from whole MIN6 cell lysates revealed the presence of heterodimers with other isoforms (Fig. 1f). Previous studies have suggested that 14-3-3 protein levels can be modulated during cell death $[21,22]$. Thus, we assessed whether the 

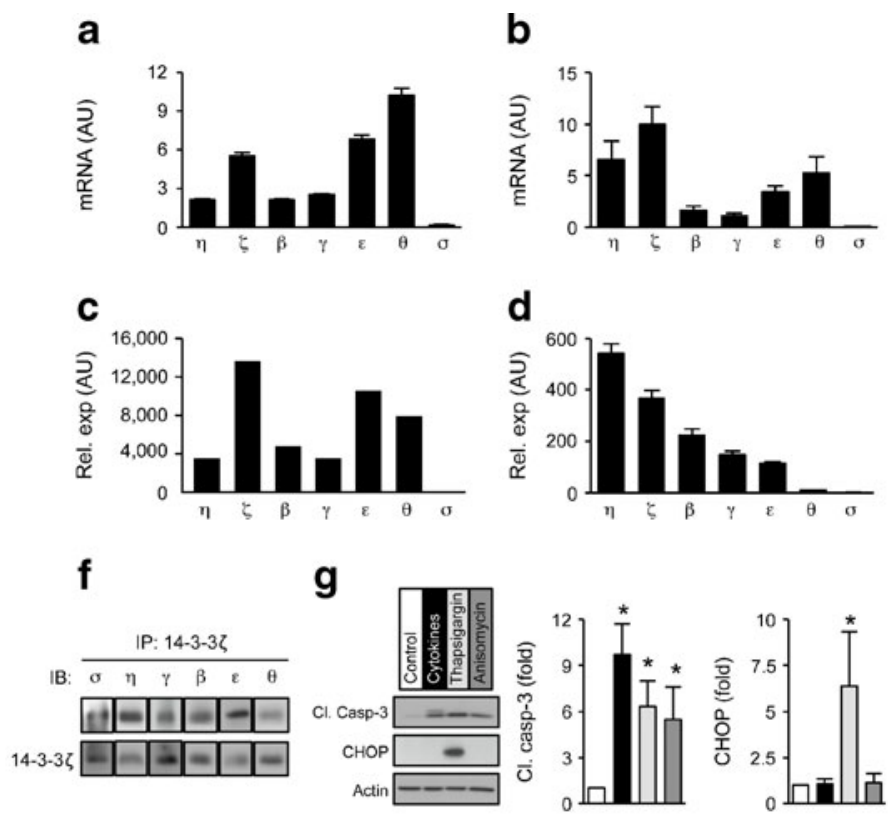

h

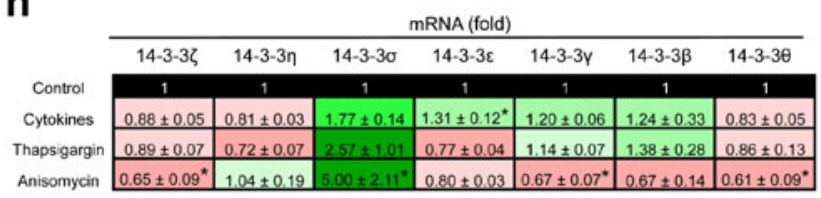

i

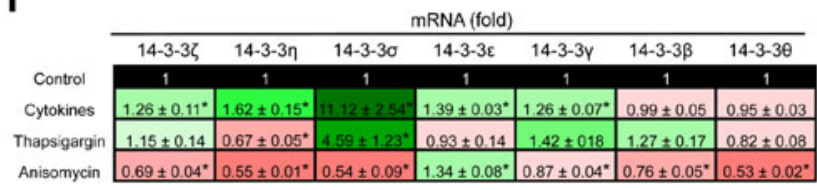

e
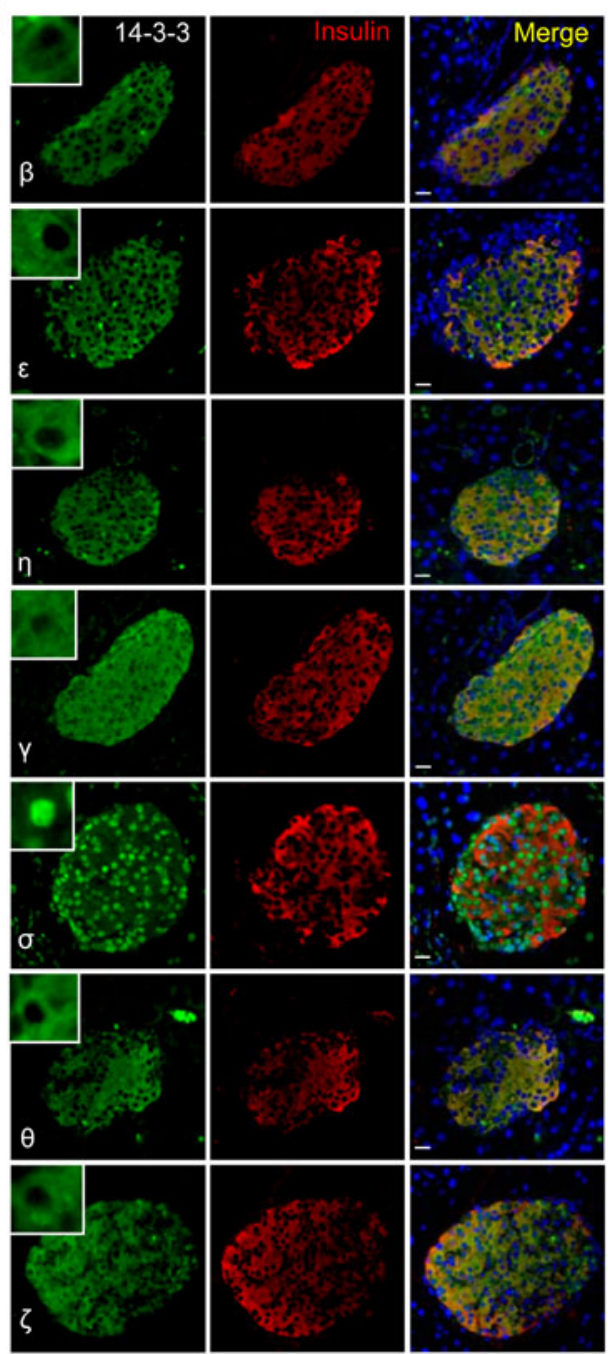
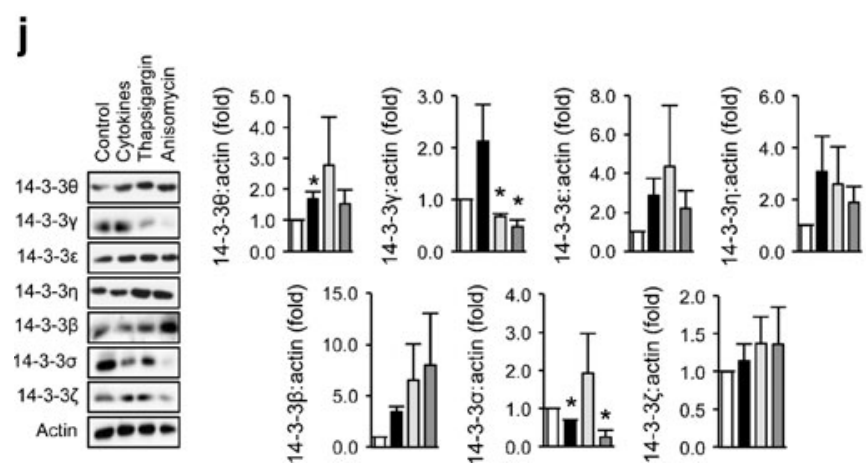

Fig. 1 14-3-3 proteins are present in pancreatic beta cells. (a) Isolated RNA from mouse islets and (b) MIN6 cells was subjected to quantitative PCR for all 14-3-3 isoforms. All data were normalised to Hprt as the endogenous control ( $n=4$ per group). (c) FACs-purified mature human $(n=2)$ and (d) mouse $(n=3)$ beta cells were subjected to Illumina gene arrays. [AU, arbitrary units; Rel. exp., relative expression] (e) Immunostaining for insulin (red) and each 14-3-3 isoform as indicated (green) was performed on wildtype C57/BL6 mouse pancreatic sections. DAPI was used to visualise nuclei. Scale bars $10 \mu \mathrm{m}$. Insets, $\times 50$ magnification of a single cell. (f) Immunoprecipitation (IP) of endogenous 14-3-3 $\zeta$ was performed on MIN6 cell lysates and probed for the remaining isoforms (blot representative of $n=$ 3 per isoform). IB, immunoblot. (g) MIN6 cells were treated for $24 \mathrm{~h}$ with

\section{k}

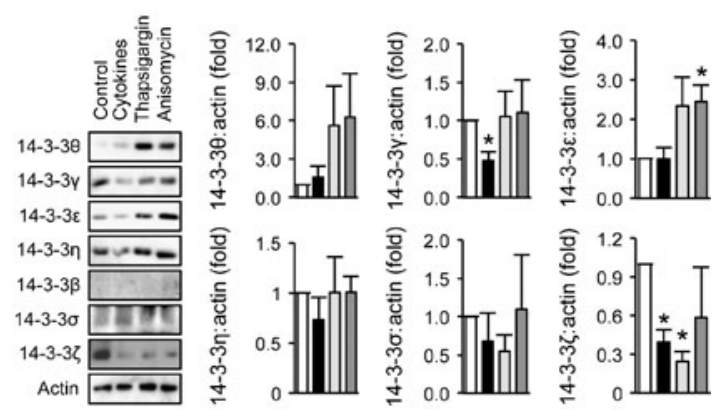

cytokines ( $25 \mathrm{ng} / \mathrm{ml} \mathrm{TNF}-\alpha, 10 \mathrm{ng} / \mathrm{ml} \mathrm{IFN}-\gamma$ or $10 \mathrm{ng} / \mathrm{ml} \mathrm{IL-1 \beta ),} 1 \mu \mathrm{mol} /$ 1 thapsigargin or $1 \mu \mathrm{mol} / 1$ anisomycin, and markers of apoptosis (cleaved caspase-3 [Cl. Casp-3]) and ER stress (CHOP) were measured by immunoblotting; $n=4$ per group; ${ }^{*} p<0.05$ compared with control cells. (h-k) Protein levels for 14-3-3 isoform transcripts (h, i) (14-3-3 $\sigma$ [also known as Sfn]; 14-3-3 [ [also known as Ywhaz]; 14-3-3 $\beta$ [also known as Ywhab]; 14-

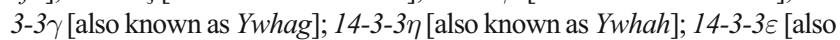
known as Ywhae]; 14-3-30 [also known as $Y w h a q])$. and protein levels (j, k) in MIN6 cells $(\mathbf{h}, \mathbf{j})$ and mouse islets $(\mathbf{i}, \mathbf{k})$ were measured by quantitative PCR or immunoblotting, following exposure to cytokines (black bars), thapsigargin (light grey bars) or anisomycin (dark grey bars); $n=4$ per group; ${ }^{*} p<0.05$ compared with control (white bars) cells 
abundance of 14-3-3 isoforms can be affected by three cellular stresses: pro-inflammatory cytokines to mimic type 1 diabetes initiation; thapsigargin to induce endoplasmic reticulum (ER) stress; and anisomycin to model JNK1/2dependent apoptosis. All stressors induced apoptosis, as detected by increases in cleaved caspase- 3 . However, the induction of ER stress, as determined by CHOP levels, was only attributed to thapsigargin treatment at the time tested (Fig. 1g). The induction of CHOP by cytokines may depend on culture conditions or species differences $[23,24]$. In MIN6 cells and mouse islets, changes in 14-3-3 isoform mRNA were detectable (Fig. 1h, i). Analysis of 14-3-3 isoforms at the protein level revealed distinct changes, including stress-induced reductions in $14-3-3 \zeta$ in primary islets (Fig. 1j, k). Collectively, these data demonstrate that all 143-3 proteins are present and their levels are regulated independently by distinct stresses in transformed and primary beta cells. Since we only analysed a single time point in our experiments, it should be noted that any apparent differences between species could be accounted for by differences in the kinetics of these responses.

Inhibition of 14-3-3 proteins decreases beta cell survival To ascertain whether 14-3-3 proteins are required in beta cell fate and function, we transfected cells with difopein, a pan14-3-3 inhibitor [11]. This induced apoptotic cell death, demonstrated by significant propidium iodide incorporation, caspase- 3 activation and BAD translocation to mitochondria (Fig. 2a-d). This is consistent with other studies suggesting that 14-3-3 proteins promote survival by sequestering proapoptotic BCL-2 proteins, such as BAD and BAX, in the cytoplasm $[4,25,26]$. Similar results were obtained after incubating MIN6 cells with a cell-permeable 14-3-3 antagonist (Fig. 2e, f). The observation that 14-3-3 inhibition causes apoptosis does not preclude roles in other forms of cell death.

We also assessed whether inhibition of 14-3-3 proteins affects insulin secretion, given their known roles in catecholamine and neurotransmitter exocytosis [27]. Analysis of glucose- and $\mathrm{KCl}$-stimulated insulin release from difopeinproducing MIN6 cells or mouse islets showed significant impairments in glucose-induced insulin release due to inhibition of 14-3-3 proteins (Fig. 2g, i). No effects on insulin content were observed (Fig. 2h, j).

To specifically examine the role of each 14-3-3 isoform, we performed a side-by-side comparison of cells with isoform-specific siRNA-mediated knockdown, which in each case significantly reduced the mRNA and protein levels of the respective targets by at least $50 \%$ and $30 \%$, respectively (Fig. 3a, b). Knockdown of each isoform did not cause any non-specific decreases in the expression of the remaining isoforms at the mRNA level (Fig. 3a), but in some cases we observed a compensatory increase in another
14-3-3 isoform, consistent with previous studies involving overexpression in other cell types [7]. Knockdown of 14-3$3 \gamma, 14-3-3 \eta, 14-3-3 \varepsilon$ and $14-3-3 \zeta$ was associated with significant induction of apoptosis (Fig. 3c). The degree of knockdown for each isoform was not identical, thus precluding an absolute ranking of their importance in beta cell survival (i.e. comparing 14-3-3 $\gamma$ with 14-3-3 ). Reductions in the $\theta, \sigma$ and $\beta$ isoforms did not induce significant apoptosis. Taken together, these findings demonstrate that certain 14-3-3 proteins regulate beta cell survival.

Overexpression of 14-3-3 5 promotes beta cell survival The high levels of the 14-3-3 $\zeta$ isoform in purified human and mouse beta cells (Fig. 1a-d), and the robust effects of 14-3$3 \zeta$ RNA interference (Fig. 3) prompted additional efforts to define the mechanisms by which $14-3-3 \zeta$ is involved in beta cell survival. $14-3-3 \zeta$ is also known to regulate the kinase activity of RAF1 [13], which we have shown to be essential for beta cell survival under serum-free in vitro conditions, where the only source of growth factors is the islets themselves (e.g. autocrine insulin signalling) [14-16, 28]. Specifically, RAF1 can prevent apoptosis by phosphorylating BAD on key serine residues that promote binding to 14-3$3 \zeta$ [14-17]. Thus, we sought to test whether 14-3-3乙 would be sufficient to protect beta cells from death under severe stress conditions. Indeed, at the time points examined, MIN6 cells overproducing 14-3-3 $\zeta$ displayed significantly reduced cell death following exposure to cytokines or thapsigargin (Fig. 4a, b), as well as decreased levels of activated caspase-3 (Fig. 4c). To examine whether this protective effect was specific to $14-3-3 \zeta$, we performed similar experiments

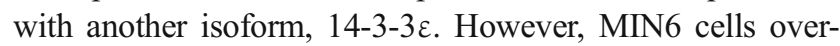
producing GFP-14-3-3 $\varepsilon$ were not protected from cytokine- or thapsigargin-mediated cell death (Fig. 4d, e). Thus, 14-3-3 $\zeta$, but not all other 14-3-3 isoforms can protect beta cells.

Pro-inflammatory cytokines activate intrinsic and extrinsic apoptotic pathways to initiate cell death [29, 30]. Previous studies on beta cells have shown that cytokines induce the dephosphorylation of BAD at Ser112 and Ser136, followed by cytoplasm-to-mitochondrial translocation of BAD to initiate apoptosis [31]. Here we confirmed that cytokine exposure stimulated the translocation of BAD to mitochondria in MIN6 cells (Fig. 5a, b). The sequestration of BAD in the cytoplasm by $14-3-3 \zeta$ is influenced by the phosphorylation of Ser112 and Ser136, which are RAF1- and Akt-targeted residues, respectively [10, 32]. Treatment of MIN6 cells with low and high doses of insulin, which we have previously demonstrated to promote the differential activation of canonical insulin signalling pathways $[15,33]$, induced the phosphorylation of BAD at Ser112 and Ser136 (Fig. 5c). Interestingly, overexpression of HA-14-3-3 $\zeta$ in MIN6 cells was associated with increased RAF1 activity as implied by the elevated basal ERK1/2 


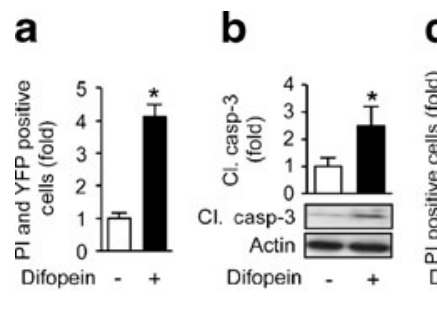

f
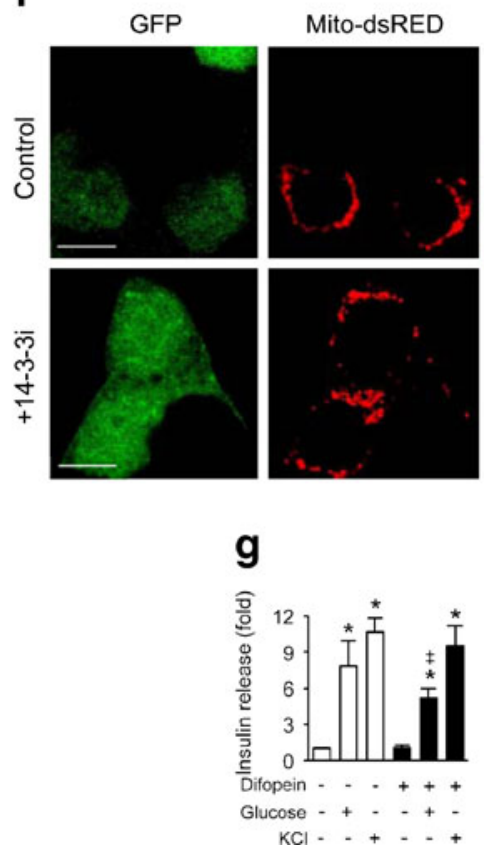

d

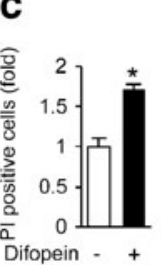

h
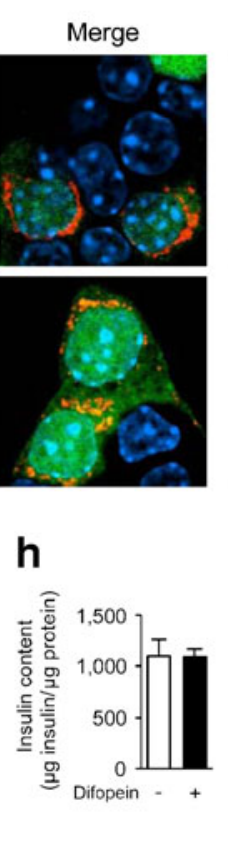
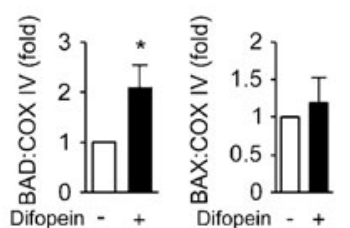

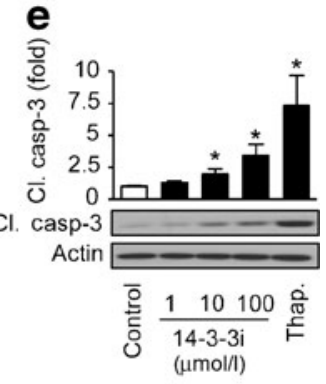

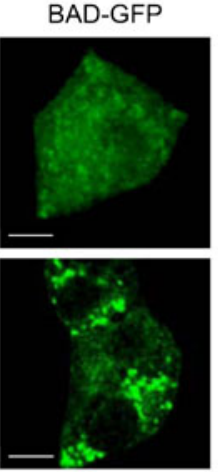
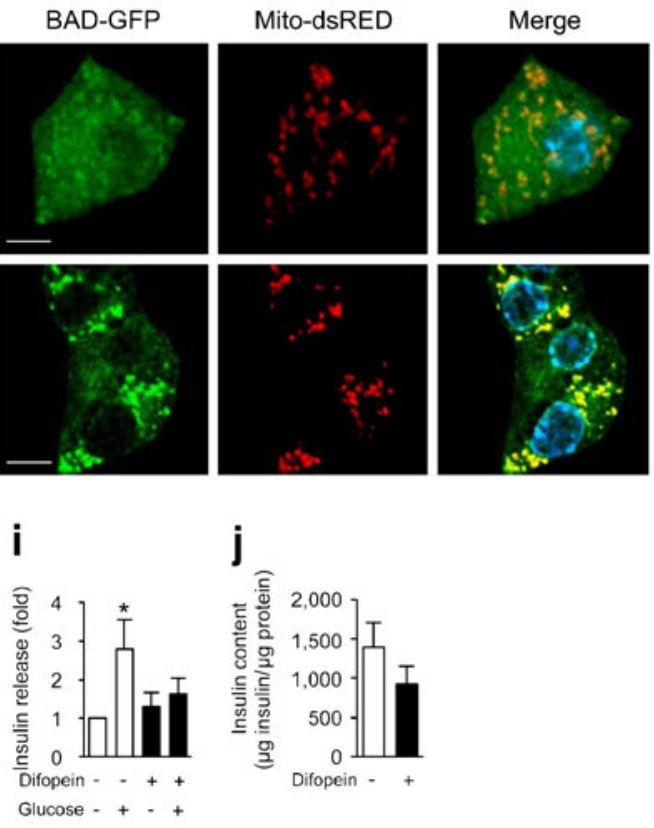

Fig. 2 14-3-3 proteins are required for beta cell survival and function. (a) MIN6 and (c) dispersed mouse islet cells were transfected with difopein-YFP, a pan-14-3-3 inhibitor, or with the empty YFP vector alone, and incubated with propidium iodide (PI) and Hoechst 33342. Dying cells were scored as being positive for PI, YFP and Hoechst 33342. (b) Cell lysates from difopein-producing MIN6 cells were resolved by SDS-PAGE and probed for levels of cleaved caspase-3 (Cl. Casp-3). (a-c) $n=6$ per group, ${ }^{*} p<0.05$. (d) Mitochondrial (Mito.) and cytoplasmic (Cyto.) fractions from control and difopein (Difo)producing cells were resolved by SDS-PAGE and probed for BAD and BAX. COX-IV and $\beta$-tubulin were used as mitochondrial and cytoplasmic loading controls, respectively. Graphs show quantifications of the mitochondrial fraction. Results are representative of $n=4$ experiments; ${ }^{*} p<0.05$. (e) MIN6 cells were treated for $24 \mathrm{~h}$ with a cell-

phosphorylation and Ser112 phosphorylation on BAD (Fig. 5c). This observation is in line with the known ability of $14-3-3 \zeta$ to modulate the kinase activity of RAF1 [13]. Moreover, insulin treatment of MIN6 cells promoted the association of pro-apoptotic BAD and BAX with endogenous 14-3-3 $\zeta$ (Fig. 5e, f). We next tested whether the increased cell survival conferred by 14-3-3 $\zeta$ overabundance was associated with altered BAD and BAX localisation. Mitochondrial fractions from cytokine-treated cells were purified from whole-cell lysates, permeable 14-3-3 antagonist (14-3-3i) or thapsigargin (Thap.; $1 \mu \mathrm{mol} /$ 1), followed by immunoblotting detection of activated caspase- 3 from cell lysates; $n=4$ per group; ${ }^{*} p<0.05$. (f) MIN6 cells co-producing BAD-GFP or GFP with mitochondria-targeted (Mito)-dsRED to visualise mitochondria were treated for $24 \mathrm{~h}$ with a 14-3-3 antagonist to detect BAD translocation to mitochondria. DAPI was used to visualise nuclei. Scale bars $10 \mu \mathrm{m}$. (g, h) MIN6 cells and (i, j) dispersed mouse islets were transfected with plasmids encoding YFP or difopein-YFP and treated with $16 \mathrm{mmol} / 1$ glucose or $25 \mathrm{mmol} / 1 \mathrm{KCl}$ for $2 \mathrm{~h}$. Secreted insulin in medium $(\mathbf{g}, \mathbf{i})$ or insulin content in cell lysates $(\mathbf{h}, \mathbf{j})$ were measured by radioimmunoassay and normalised to total protein; $n=3$ 6 per group; ${ }^{*} p<0.05$ compared with the untreated control, ${ }^{\dagger} p<0.05$ compared with control vector-treated cells

and when compared with control vector-transfected cells, overabundance of 14-3-3 $\zeta$ prevented cytokine-induced translocation of BAD and BAX to mitochondria and led to an increase in their cytoplasmic distribution (Fig. 5d). Co-immunoprecipitation showed that insulin promoted the association of HA-14-3-3 $\zeta$ with BAD and BAX (Fig. 5g). Together, these data suggest that overabundance of 14-3-3 $\zeta$ can inhibit cytokine-mediated cell death through sequestration of $\mathrm{BAD}$ and $\mathrm{BAX}$ in the cytoplasm. 
Fig. 3 Knockdown of each 143-3 isoform demonstrates differential roles in cell survival. (a) Knockdown efficiency (50\% or greater) and expression of remaining isoform transcripts as indicated following transfection with isoform-specific siRNAs $(100 \mathrm{nmol} / \mathrm{l})$ were measured by quantitative PCR; $n=4$ per group; ${ }^{*} p<0.05$ compared with scrambled (siCon)-transfected cells. (b) Lysates from siRNAtransfected cells were resolved by SDS-PAGE and probed for the corresponding 14-3-3 isoform. Actin was used as a loading control and the fold change in abundance of each isoform was normalised to scrambled (siCon) siRNAtransfected cells; $n=4$ per group. (c) Apoptosis was measured in siRNA-transfected cells by immunoblotting for cleaved caspase-3 (Cl. casp-3). Data were normalised to actin as a loading control; $n=4$ per group; ${ }^{*} p<0.05$ a
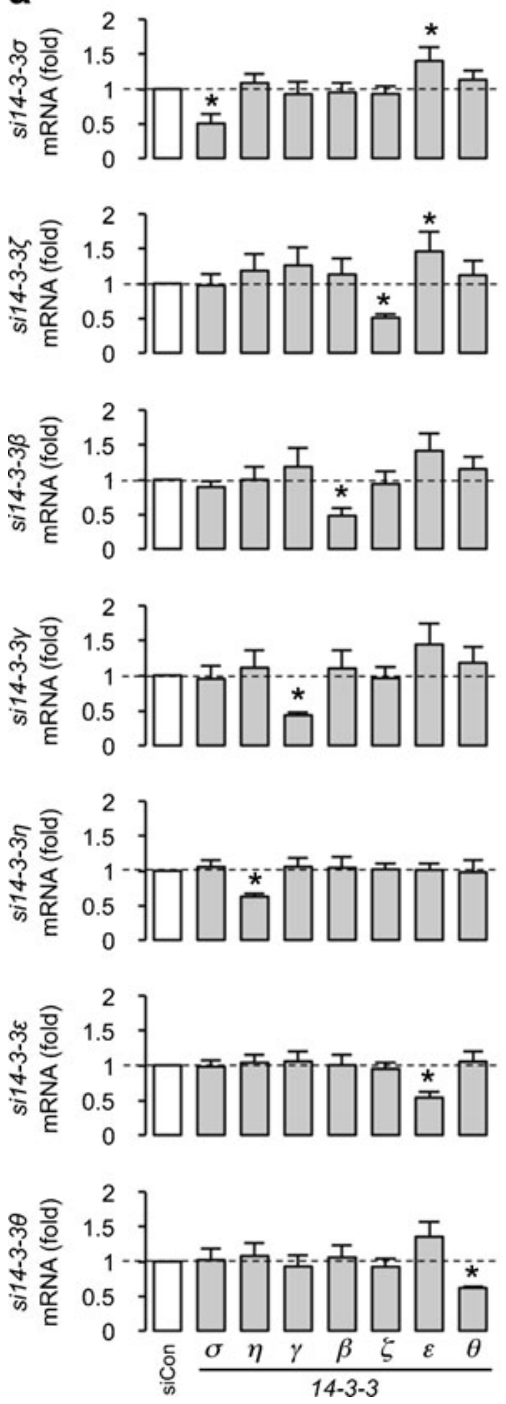

b
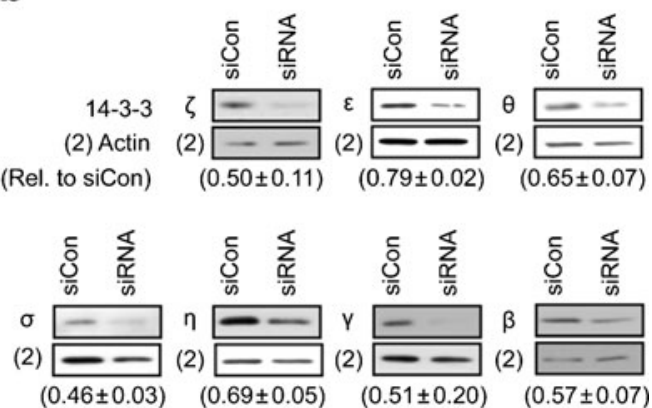

C

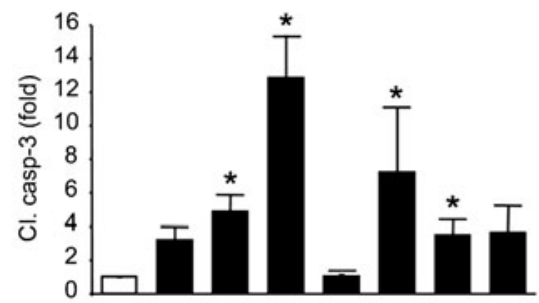

Cl. casp-3

Actin

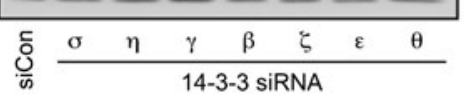

To further examine whether the serine phosphorylation of BAD is critical for its localisation and apoptotic activity, BAD-GFP mutants containing single serine-to-alanine mutations at S112A or S136A or a double S112A/S136A mutation, were overproduced in MIN6 cells. A triple mutant (S112A/S136A/S155A) lacking a PKA-phosphorylation site served as a control, as it lacks all inhibitory phosphorylation sites [34]. Wild-type BAD-GFP was predominantly retained in the cytoplasm; however, all other mutants showed increased localisation to mitochondria (Fig. 6a, b). Overabundance of wild-type BAD or Ser112A BAD resulted in modest increases in programmed cell death, as measured by propidium iodide incorporation or activated cleaved caspase-3 levels (Fig. 6c, d), but cells producing the S136A, double mutation or triple mutation BAD-GFP proteins demonstrated much larger increases $(p<0.05)$ in dying cells and cleaved caspase- 3 levels. These data suggest that in the beta cell, the interaction of BAD with $14-3-3 \zeta$ is a fundamental signalling event that regulates survival.
Regulation of BCL-2 protein levels by 14-3-3 $\zeta$ Apart from their ability to bind pro-apoptotic BCL-2 proteins, 14-33 proteins can also regulate the nuclear factor $\mathrm{KB}$ $(\mathrm{NF} K \mathrm{~B})$ and JNK1/2 signalling pathways $[35,36]$, both of which mediate cytokine-induced expression of apoptosis-regulating genes, including members of the BCL-2 family [37-39]. Both pathways were clearly activated by cytokines in MIN6 cells (Fig. 7a-c), as evidenced by increased phosphorylation of the p65/RelA transcription factor and by increased phosphorylation of JNK1/2. These events were attenuated in cells overpro-

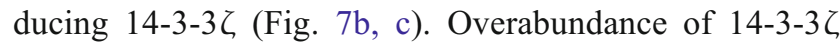
did not affect the cytokine-induced transcription of a large number of canonical apoptosis-regulating genes (Fig. 7d-i). However, we did find that 14-3-3 $\zeta$ overabundance did abrogate the cytokine-induced increase in mRNA levels of Puma (also known as Bbc3) and the BH3-only sensitiser, Dp5 (also known as Hrk) (Fig. 7n, o) [38-40]. Taken together, these findings suggest that 


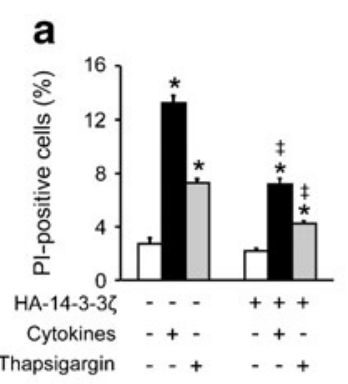

d

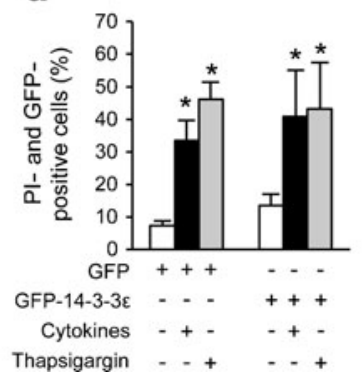

e

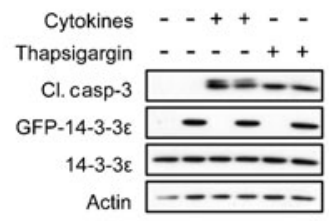

Actin

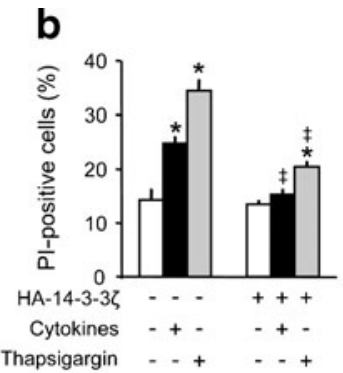

c
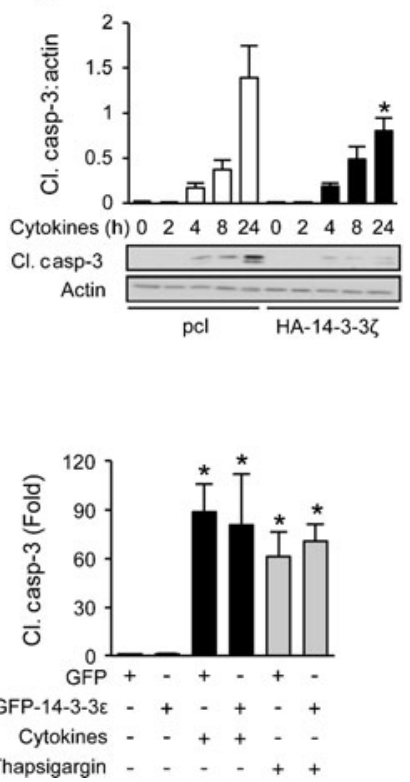

Fig. 4 Overabundance of $14-3-3 \zeta$ promotes beta cell survival. (a) MIN6 cells were transfected with plasmids encoding HA-14-3-3 $\zeta$ or the control vector, and cell death, as assessed by propidium iodide (PI) incorporation, was measured in cells exposed to cytokines $(25 \mathrm{ng} / \mathrm{ml}$ TNF- $\alpha, 10 \mathrm{ng} / \mathrm{ml} \mathrm{IL-1} \beta, 10 \mathrm{ng} / \mathrm{ml} \mathrm{IFN}-\gamma)$ or thapsigargin $(1 \mu \mathrm{mol} / \mathrm{l})$ for $24 \mathrm{~h}$ or (b) for $48 \mathrm{~h} ; n=4-6$ per group; ${ }^{*} p<0.05$ compared with the empty vector or untreated control; ${ }^{\dagger} p<0.05$ compared with the empty vector treatment. (c) MIN6 cells were transfected with plasmids encoding HA-14-3-3 $\zeta$ or the control vector $(\mathrm{pcl})$ and treated with cytokines at various time points. Cell lysates were resolved by SDS-PAGE and

14-3-3 $\zeta$ may promote cell survival through the suppression of specific pro-apoptotic BCL-2 genes.

\section{Discussion}

In the present study, we sought to survey all 14-3-3 protein isoforms and we chose a single isoform for detailed molecular mechanistic studies. Our data demonstrate that all seven members are present in pancreatic beta cells, with distinct distribution patterns and differential regulation and roles in cell survival. We identified $14-3-3 \zeta$ as a critical signalling hub, which prevents beta cell death through multiple mechanisms. Our findings suggest that modulating the activity or levels of 14-3-3 $\zeta$ could be a way to prevent beta cell apoptosis and diabetes.

The 14-3-3 family of proteins, first characterised in brain [4], consists of molecular adaptors that recognise phosphorylated proteins (e.g. kinases, transcription factors and receptors). They are able to coordinate almost limitless combinations of protein complexes, which accounts for their functional diversity [3-5, 26]. A previous report established that one isoform is present in beta cells [41], but without an in-depth investigation of its physiological function. In the immunoblotted for cleaved caspase-3 (Cl. casp-3). Actin was used as a loading control. Results are representative of $n=4$ experiments; ${ }^{*} p<$ 0.05 compared with control vector-treated cells. (d) MIN6 cells were transfected with plasmids encoding GFP or GFP-14-3-3 $\varepsilon$, and subsequently treated with cytokines or thapsigargin for $24 \mathrm{~h}$. Cell death was measured by determining PI incorporation in GFP-positive cells or (e) by detecting levels of activated caspase- 3 in cell lysates by SDSPAGE; $n=4$ per group; $* p<0.05$ compared with untreated, GFPtransfected cells

present study, inhibition of 14-3-3 function with difopein or a cell-permeable inhibitor promoted cell death, but the differential regulation of isoform levels by cellular stressors

Fig. 5 14-3-3 $\zeta$ facilitates cell survival through its interactions with BAD. (a) MIN6 cells producing GFP or (b) wild-type BAD-GFP, and (a, b) dsRed targeted to mitochondria (Mito-dsRed) were treated with cytokines for $24 \mathrm{~h}$ and imaged. DAPI was used to visualise nuclei. Scale bars $10 \mu \mathrm{m}$. (c) MIN6 cells transfected with the control vector or

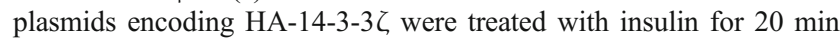
and subsequently lysed. Lysates were resolved by SDS-PAGE and immunoblotted for activation markers of the canonical insulin signalling pathways as indicated; $n=4$ per group; $* p<0.05$ compared with untreated, control cells; ${ }^{\dagger} p<0.05$ compared with insulin-treated control cells. (d) Mitochondrial and cytoplasmic fractions were purified from whole-cell lysates from control and cytokine-treated MIN6 cells transfected with the vector control or HA-14-3-3 $\zeta$ plasmids, and immunoblotting was used to measure the abundance of BAD and BAX in each fraction. COX-IV and $\beta$-tubulin were used as mitochondrial and cytoplasmic loading controls, respectively; $n=4$ per group; ${ }^{*} p<0.05$. (e, f) Immunoprecipitation (IP) of 14-3-3, , (e) or BAD or BAX from MIN6 lysates, followed by immunoblot analysis, was performed to determine the association of BAD and BAX with 14-3-3 $\zeta$ after treatment with insulin or glucagon-like peptide 1 (GLP-1). Blots are representative of $n=4$ experiments; ${ }^{*} p<0.05$ when compared to untreated cells. (g) HA pull-down assays were performed on MIN6 cells that were overabundant in HA-14-3-3 $\zeta$ and were treated with insulin, with immunoblotting used to measure $\mathrm{BAD}$ and $\mathrm{BAX}$ association. Blots are representative of $n=4$ experiments; ${ }^{*} p<0.05$ when compared to untreated cells 
suggested isoform-specific roles in apoptosis. In primary islets, 14-3-3 $\zeta$ levels were significantly reduced by cytokines and thapsigargin, suggesting a possible role for this isoform in survival. While differences between MIN6 cells and mouse islets were observed in response to the cellular stressors at the time point tested, our data do not rule out similar responses at different time points.
The roles of each endogenous 14-3-3 protein in cell survival were tested by isoform-specific RNA interference that was validated for off-target effects against remaining family members. Different degrees of cell death were observed following knockdown of each isoform, an unexpected finding, given a previous report that in Cos7 cells each isoform inhibits BAD-induced apoptosis to equal degrees a
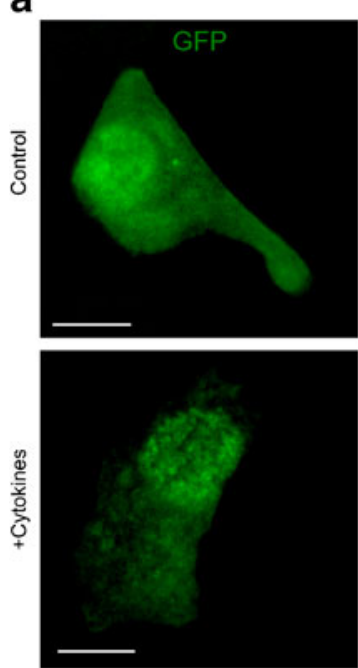

b
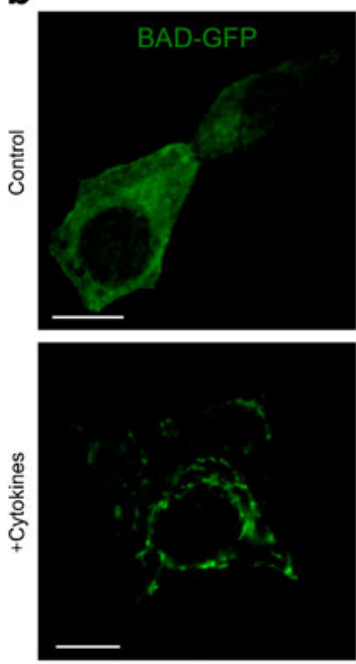

d
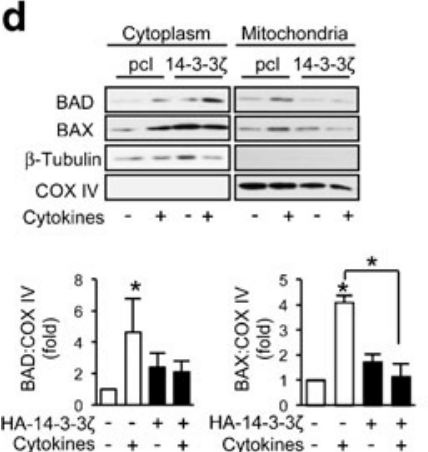
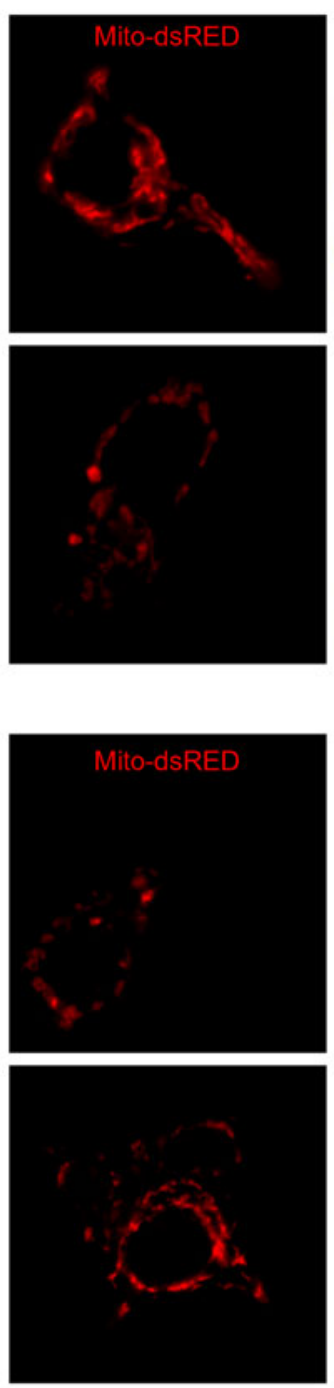

e

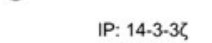

0.2 nmol/ Ins $-14-3-3 \zeta$

$200 \mathrm{nmo} / / \mathrm{Ins}-\mathrm{I}_{-}+$

$10 \mathrm{nmol} / / \mathrm{GLP}-1$ - . - +

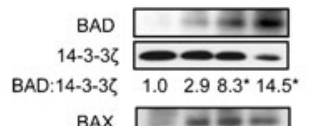

BAX ---

14-3-3ל

BAX:14-3-3Z $1.01 .64 .4^{*} 4.6^{*}$
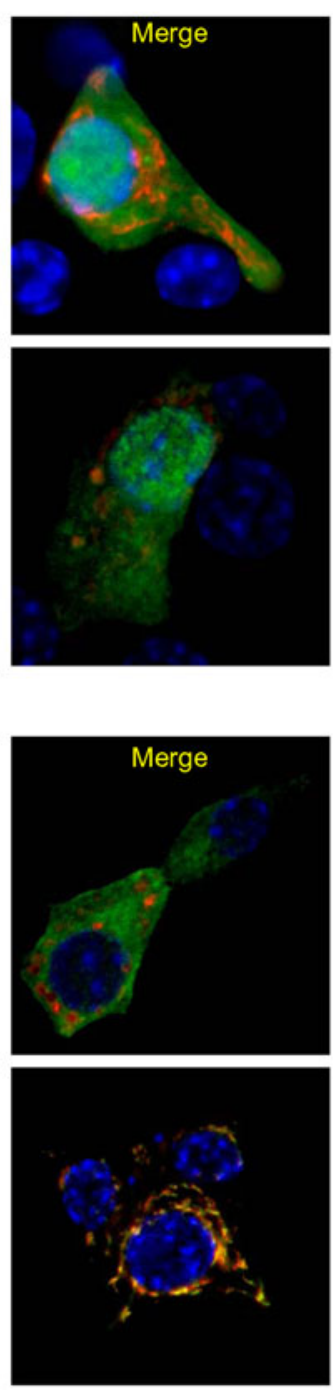

f

0.2 nmoll Ins

$200 \mathrm{nmol} / \mathrm{l} / \mathrm{ns}$

$10 \mathrm{nmol} / / \mathrm{GLP}-1$

IP:BAD ${ }_{\text {BAD }}^{14-3-3 \zeta}$

14-3-3द: BAD $1.0 \quad 2.8^{*} 1.8 \quad 2.5^{*}$

IP:BAX ${ }_{\text {BAX }}^{14-3-3 \zeta}$

14-3-3द: BAX $1.02 .1 * 1.71 .3$ c

$0.2 \mathrm{nmol} / \mathrm{insulin}-\cdot++\cdot-$

$200 \mathrm{nmol} / \mathrm{insulin} \mathrm{-} \mathrm{.} \mathrm{+} \mathrm{++}$

HA-14-3-3 $-+\cdots+\cdot+$
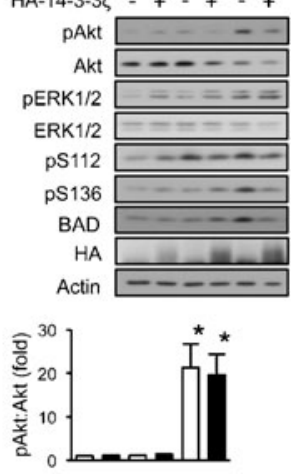

HA-14-3-33 - + + + +

\begin{tabular}{lrr}
0 & $0.2 \quad 200$ \\
\hline Insulin $(\mathrm{nmol} / \mathrm{l})$
\end{tabular}

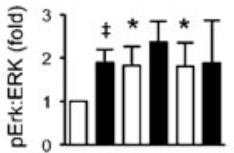

$\mathrm{HA}-14-3-3 \mathrm{Z}=+\cdots+$

$$
\begin{array}{lll}
0 & 0.2 \quad 200 \\
\hline \text { Insulin }(\mathrm{nmol} / \mathrm{l})
\end{array}
$$
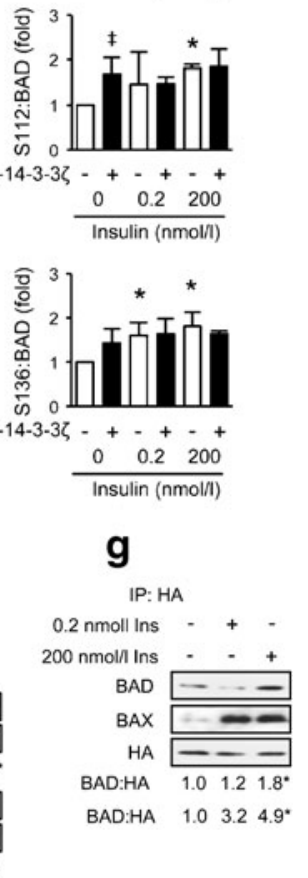
Fig. 6 Impaired interactions of BAD with $14-3-3 \zeta$ promotes cell death. (a) The localisation of wild-type (WT) BAD-GFP and Ser-Ala point mutants was visualised in MIN6 cells cotransfected with mitochondriatargeted (Mito)-dsRED. DAPI was used to visualise nuclei. Scale bars $10 \mu \mathrm{m}$. DM, double mutation; TM, triple mutation. (b) MIN6 cells overproducing wild-type BAD-GFP or SerAla mutants were lysed and the distribution of GFP-conjugated proteins was examined in mitochondrial and cytoplasmic fractions. COX-IV and $\beta$ tubulin were used as loading controls for mitochondrial and cytoplasmic fractions, respectively, to quantify the relative levels of each BAD mutant in mitochondrial fractions; $n=4$ per group; ${ }^{*} p<0.05$ compared with wild-type BAD-GFP. (c) Apoptosis induced by overabundance of wild-type BAD-GFP or the Ser-Ala mutants was measured in MIN6 cells by propidium iodide (PI) incorporation or (d) by immunoblotting for cleaved caspase-3 (Cl. casp-3); $n=4$ per group; ${ }^{*} p<0.05$
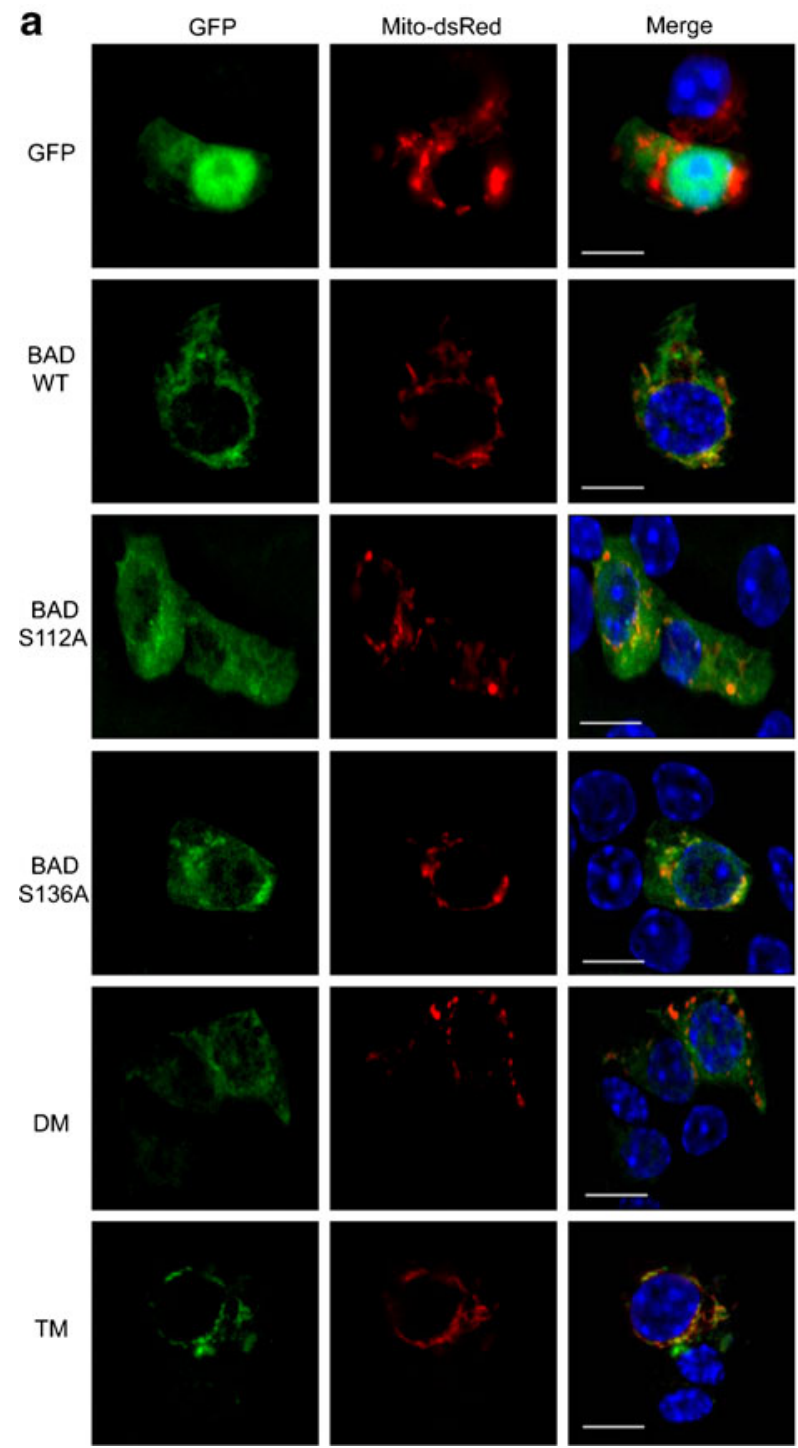

\section{b}
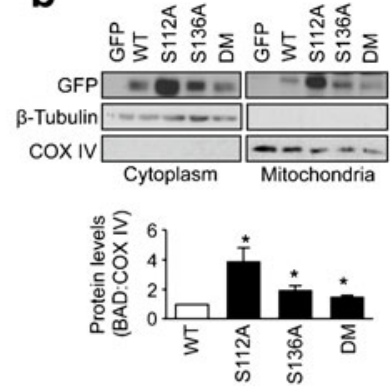

C

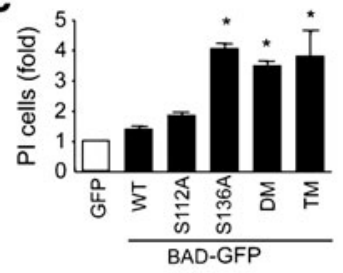

d

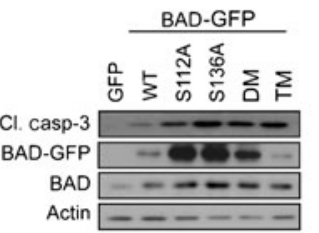

[7]. The differences observed in cell death can be attributed to each isoform having unique interactomes, as structural analysis of the 14-3-3 family revealed a highly variable region between $\alpha$-helices 8 and 9, which determines binding specificity [42]. This concept has been validated in screens of human 14-3-3 binding partners, which revealed common and unique protein $\times$ protein interactions among the tested isoforms [43]. Further work is required to examine the interactome of each 14-3-3 isoform in beta cells.

One of the defining characteristics of type 1 diabetes is the profound loss of beta cell mass induced by proinflammatory cytokines and linked, by some investigators, to ER stress $[1,2,29]$. The survival of pancreatic beta cells under normal and diabetic conditions is influenced by the balance of pro-survival growth factors, including insulin itself $[1,2,14-17]$. We have previously identified the key insulin signalling component, RAF1, as a contextdependent regulator of pancreatic beta cell survival and function [14-17]. Our decision to focus on $14-3-3 \zeta$ was in part due to its ability to regulate the kinase activity of RAF1, which phosphorylates pro-apoptotic BAD on Ser112, a 143-3 binding site [13, 44]. The 14-3-3 $\zeta$ isoform was also the most highly abundant isoform in FACS-purified human beta cells. Although knockdown of 14-3-3 $\gamma$ led to the highest degree of caspase- 3 activity, its abundance in mouse and human beta cells was one of the lowest among 14-3-3 isoforms, thus reinforcing our decision to focus on the $\zeta$ isoform. Our observations that 14-3-3 $\zeta$ knockdown or overabundance promoted apoptosis or cell survival was consistent with evidence from other cell types $[9,45]$, suggesting an essential role for 14-3-3 $\zeta$ in beta cell survival.

Life and death decisions in pancreatic beta cells are modulated by proteins of the BCL-2 family [29, 30, 46]. Following phosphorylation by pro-survival signals, BAD dissociates from BCLXL and is sequestered by 14-3-3 proteins in the cytosol $[10,25,44]$. In the present study, phosphorylation of BAD following insulin exposure induced binding with $14-3-3 \zeta$, thus demonstrating a direct 
a

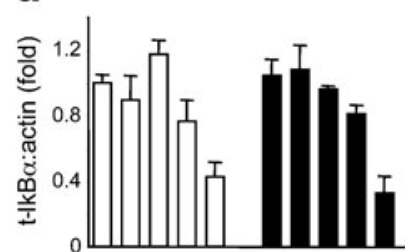

$\mathrm{IkB} \alpha-\infty-\cdots$

Actin $-1--\cdots$

Time (h) $\begin{array}{llllllllll}0 & 2 & 4 & 8 & 24 & 0 & 24 & 4 & 84 \\ \end{array}$

\section{b}

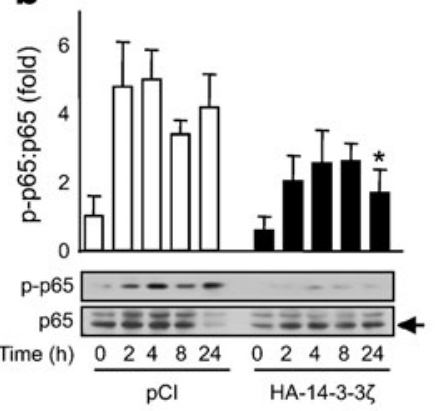

C

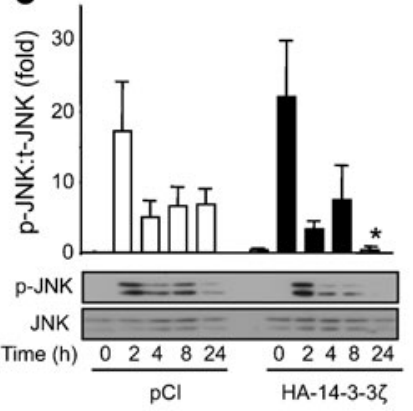

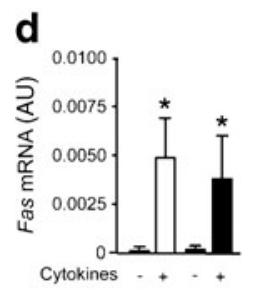
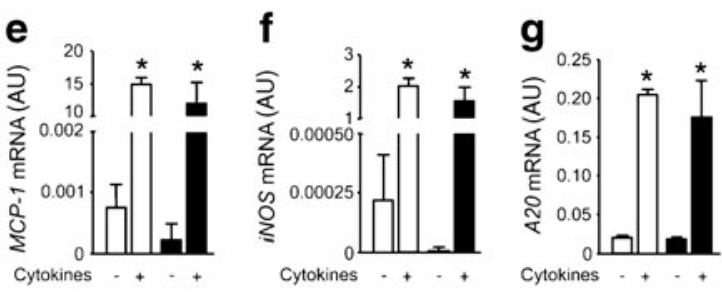

h
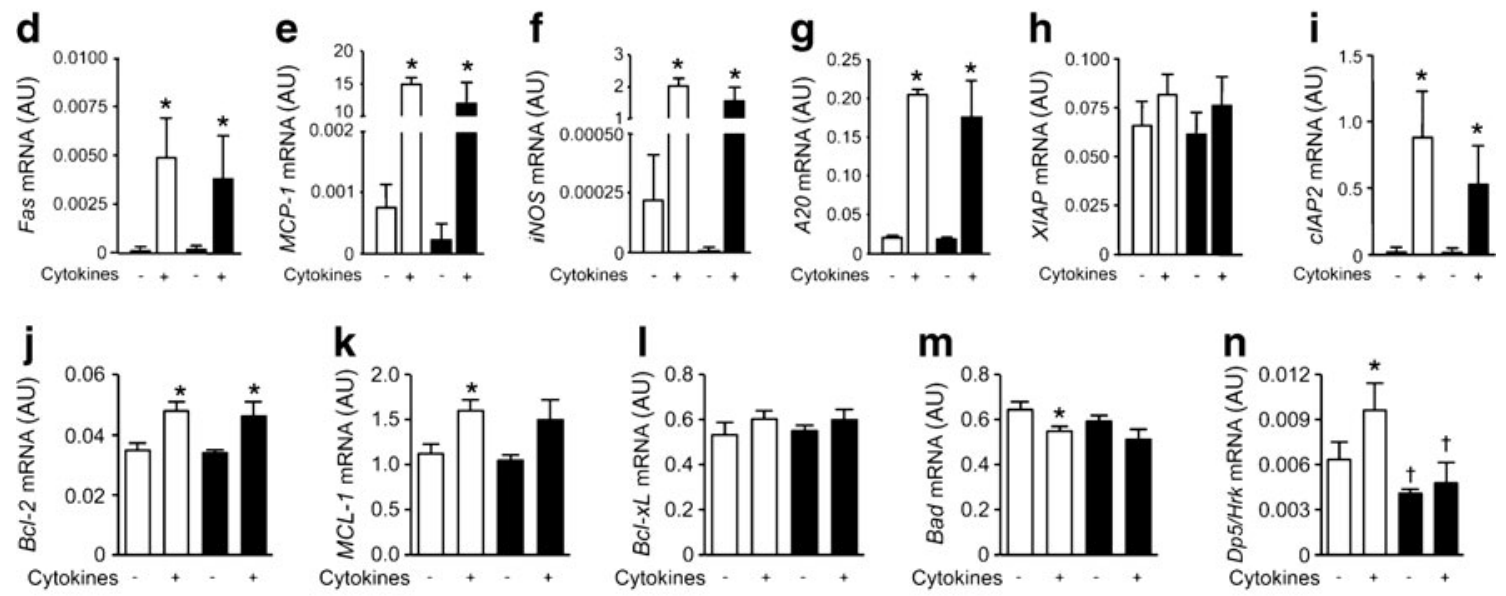

m
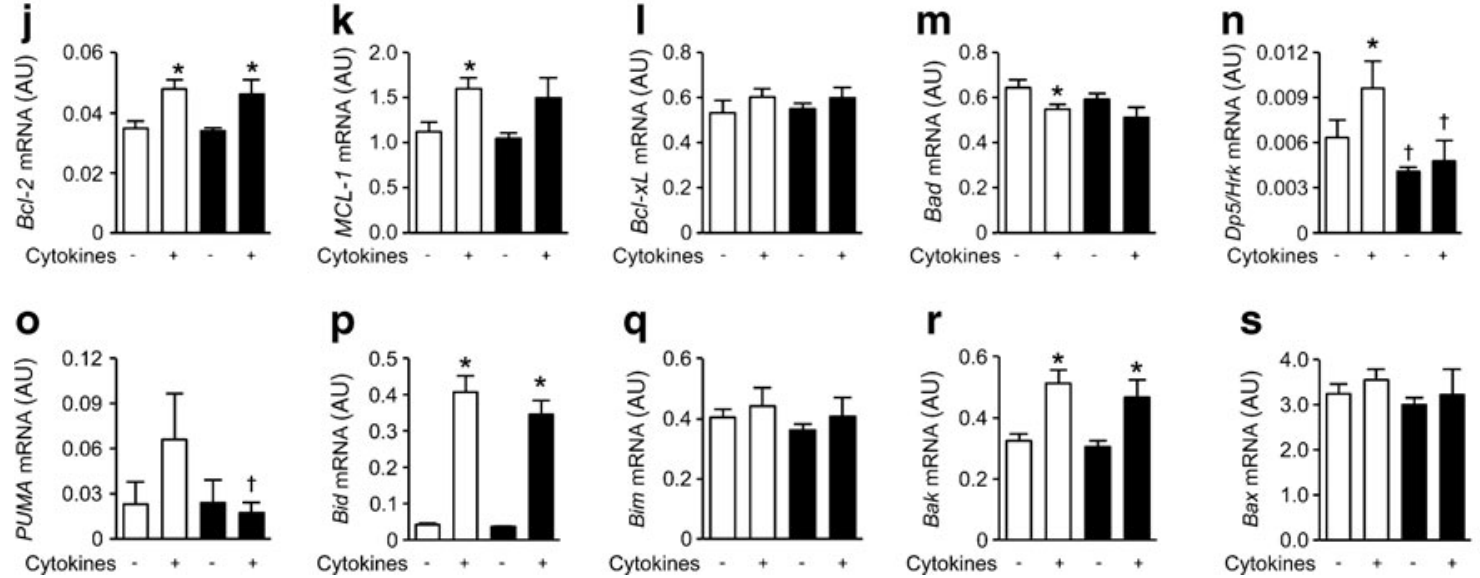

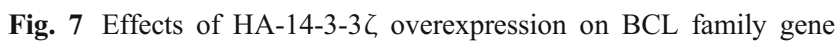
expression. (a-c) MIN6 cells transfected with plasmids encoding HA-

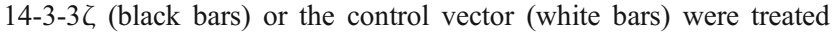
with cytokines. Cell lysates were resolved by SDS-PAGE and probed for markers of activation of the NFKB $(\mathbf{a}, \mathbf{b})$ and SAPK-JNK1/2 (c) signalling pathways; $n=4-6$ per group; ${ }^{*} p<0.05$ compared with empty vector-treated cells. $\mathrm{IkB} \alpha$, nuclear factor of kappa light polypeptide gene enhancer in B-cells inhibitor, alpha; t, total. (d-i) Transcript levels of canonical pro-apoptotic and survival pathways, and $(\mathbf{j}-\mathbf{s})$ of members of the BCL-2 protein family as indicated by labelling were

relationship between these proteins. Binding with 14-3-3乙 does not require Ser112 and Ser136 to be doubly phosphorylated [44], and it is unclear which serine residues play a predominant role in 14-3-3 binding [10, 12]. Our data suggest that, in beta cells, Ser136 is critical for survival, as overabundance of the S136A mutant was associated with the greatest degree of cell death. It should be noted that the pro-survival actions of $14-3-3 \zeta$ are not solely limited to its effect on $\mathrm{BAD}$, as overabundance of $14-3-3 \zeta$ retained BAX in the cytoplasm following cytokine exposure. Furthermore, overabundance of 14-3-3 $\zeta$ also suppressed cytokinemediated increases in Dp5 and Puma mRNA, which are measured by quantitative PCR using isolated RNA from MIN6 cells transfected with the control vector (white bars) or with plasmids encoding HA-14-3-3 $\zeta$ (black bars) and subsequently treated with cytokines for $24 \mathrm{~h}$. All data (arbitrary units [AU]) were normalised to Hprt; $n=4$ per group; ${ }^{*} p<0.05$ compared with untreated control cells; ${ }^{\dagger} p<0.05$ compared with control treated cells. $M c p-1$, also known as Ccl2; iNos, also known as Nos2; A20, also known as Tnfaip3; clap2, also known as Birc3; Bclxl, also known as Bcl2ll; Bim, also known as $B c l 2 l 11 ; B a k$, also known as Bakl

dependent on activation of the ASK1-JNK and NFKB signalling pathways, respectively [38-40].

Interestingly, transgenic mice overexpressing the triple Ser-Ala (112/136/155) BAD mutant were glucoseintolerant due to decreased glucokinase activity in islets [47]. This observed decrease in glucokinase activity was due to the phosphorylation status of BAD, which we found to be critical for its cellular localisation in beta cells (Fig. 6a, b). Similarly, difopein overproduction in beta cells blunted glucose-stimulated insulin release and promoted BAD translocation to mitochondria. Taken together, these findings suggest that $14-3-3 \zeta$ may act as a unique scaffold of BAD 
that determines cellular localisation and, ultimately, 14-3$3 \zeta$ 's dual roles in metabolism and cell survival.

Collectively, our data demonstrate an important role of the 14-3-3 proteins in pancreatic beta cell survival and function. To date, the regulatory mechanisms and pathways that control the abundance of each isoform are not fully known, nor are the prevalence and mechanisms of isoform-specific functions well understood [6]. We determined multiple mechanisms by which 14-3-3 $\zeta$ promotes survival (electronic supplementary material [ESM] Fig. 1). Further work is required to dissect the roles of the remaining 14-3-3 isoforms. Our observations raise the possibility that therapeutic approaches, designed to increase the levels or activity of 14-3-3 proteins, could protect beta cells from death during diabetes [2]. Interestingly, the inhibition of 14-3-3 proteins has been proposed as a potential novel approach for the treatment of some cancers [48], an approach that, based on our results, could have deleterious effects on beta cell survival and potentially on glucose homeostasis. Further work is therefore required to evaluate the role of 14-3-3 proteins in other tissues important for glucose homeostasis.

In conclusion, we report for the first time that certain 143-3 proteins are required for the determination of beta cell fate and function. Despite structural similarities, 14-3-3 family members appear to have distinct roles in beta cell survival. Overabundance of 14-3-3 $\zeta$ increased survival via actions on BCL-2 proteins. Modulation of the levels or function of this isoform, and perhaps others, could be a novel approach to prevent beta cell death.

Acknowledgements G.E. Lim was supported by postdoctoral fellowships from the Canadian Institutes of Health Research (CIHR) and the Michael Smith Foundation for Health Research (MSFHR).

Funding This work was supported by a Juvenile Diabetes Research Foundation Research Grant (1-2011-652) to J.D. Johnson.

Duality of interest The authors declare that there is no duality of interest associated with this manuscript.

Contribution statement GEL designed and performed experiments, and wrote the manuscript. MP performed experiments, analysed data and edited the manuscript. JDJ designed experiments and edited the manuscript. All authors have approved the final version to be published.

\section{References}

1. Prentki M, Nolan CJ (2006) Islet beta cell failure in type 2 diabetes. J Clin Invest 116:1802-1812

2. Harlan DM, Kenyon NS, Korsgren O, Roep BO (2009) Current advances and travails in islet transplantation. Diabetes 58:2175-2184

3. Scott JD, Pawson T (2009) Cell signaling in space and time: where proteins come together and when they're apart. Science 326:1220-1224
4. Morrison DK (2009) The 14-3-3 proteins: integrators of diverse signaling cues that impact cell fate and cancer development. Trends Cell Biol 19:16-23

5. Petosa C, Masters SC, Bankston LA et al (1998) 14-3-3zeta binds a phosphorylated Raf peptide and an unphosphorylated peptide via its conserved amphipathic groove. J Biol Chem 273:16305-16310

6. Rosenquist M, Sehnke P, Ferl RJ, Sommarin M, Larsson C (2000) Evolution of the 14-3-3 protein family: does the large number of isoforms in multicellular organisms reflect functional specificity? J Mol Evol 51:446-458

7. Subramanian RR, Masters SC, Zhang H, Fu H (2001) Functional conservation of 14-3-3 isoforms in inhibiting bad-induced apoptosis. Exp Cell Res 271:142-151

8. Lau JM, Wu C, Muslin AJ (2006) Differential role of 14-3-3 family members in Xenopus development. Dev Dyn 235:1761-1776

9. Xing H, Zhang S, Weinheimer C, Kovacs A, Muslin AJ (2000) 143-3 proteins block apoptosis and differentially regulate MAPK cascades. EMBO J 19:349-358

10. Datta SR, Katsov A, Hu L et al (2000) 14-3-3 proteins and survival kinases cooperate to inactivate $\mathrm{BAD}$ by $\mathrm{BH} 3$ domain phosphorylation. Mol Cell 6:41-51

11. Masters SC, Fu H (2001) 14-3-3 proteins mediate an essential antiapoptotic signal. J Biol Chem 276:45193-45200

12. Chiang CW, Kanies C, Kim KW et al (2003) Protein phosphatase 2A dephosphorylation of phosphoserine 112 plays the gatekeeper role for BAD-mediated apoptosis. Mol Cell Biol 23:6350-6362

13. Fantl WJ, Muslin AJ, Kikuchi A et al (1994) Activation of Raf-1 by 14-3-3 proteins. Nature 371:612-614

14. Alejandro EU, Johnson JD (2008) Inhibition of Raf-1 alters multiple downstream pathways to induce pancreatic beta-cell apoptosis. J Biol Chem 283:2407-2417

15. Alejandro EU, Kalynyak TB, Taghizadeh F et al (2010) Acute insulin signaling in pancreatic beta-cells is mediated by multiple Raf-1 dependent pathways. Endocrinology 151:502-512

16. Alejandro EU, Lim GE, Mehran AE et al (2011) Pancreatic betacell Raf-1 is required for glucose tolerance, insulin secretion, and insulin 2 transcription. FASEB J 25:3884-3895

17. Beith JL, Alejandro EU, Johnson JD (2008) Insulin stimulates primary beta-cell proliferation via Raf-1 kinase. Endocrinology 149:2251-2260

18. Barry EF, Felquer FA, Powell JA et al (2009) 14-3-3:Shc scaffolds integrate phosphoserine and phosphotyrosine signaling to regulate phosphatidylinositol 3-kinase activation and cell survival. J Biol Chem 284:12080-12090

19. Szabat M, Luciani DS, Piret JM, Johnson JD (2009) Maturation of adult beta-cells revealed using a Pdx1/insulin dual-reporter lentivirus. Endocrinology 150:1627-1635

20. Szabat M, Pourghaderi P, Soukhatcheva G et al (2011) Kinetics and genomic profiling of adult human and mouse beta-cell maturation. Islets 3:175-187

21. He M, Zhang J, Shao L et al (2006) Upregulation of 14-3-3 isoforms in acute rat myocardial injuries induced by burn and lipopolysaccharide. Clin Exp Pharmacol Physiol 33:374-380

22. Kuzelova K, Grebenova D, Pluskalova M, Kavan D, Halada P, Hrkal Z (2009) Isoform-specific cleavage of 14-3-3 proteins in apoptotic JURL-MK1 cells. J Cell Biochem 106:673-681

23. Akerfeldt MC, Howes J, Chan JY et al (2008) Cytokine-induced beta-cell death is independent of endoplasmic reticulum stress signaling. Diabetes 57:3034-3044

24. Lai E, Bikopoulos G, Wheeler MB, Rozakis-Adcock M, Volchuk A (2008) Differential activation of ER stress and apoptosis in response to chronically elevated free fatty acids in pancreatic beta-cells. Am J Phyisol Endocrinol Metabol 294:E540-E550

25. Masters SC, Yang H, Datta SR, Greenberg ME, Fu H (2001) 14-33 inhibits Bad-induced cell death through interaction with serine136. Mol Pharmacol 60:1325-1331 
26. Tsuruta F, Sunayama J, Mori Y et al (2004) JNK promotes Bax translocation to mitochondria through phosphorylation of 14-3-3 proteins. EMBO J 23:1889-1899

27. Morgan A, Burgoyne RD (1992) Exo1 and Exo2 proteins stimulate calcium-dependent exocytosis in permeabilized adrenal chromaffin cells. Nature 355:833-836

28. Johnson JD, Alejandro EU (2008) Control of pancreatic beta-cell fate by insulin signaling: the sweet spot hypothesis. Cell Cycle $7: 1343-1347$

29. Cnop M, Welsh N, Jonas JC, Jorns A, Lenzen S, Eizirik DL (2005) Mechanisms of pancreatic beta-cell death in type 1 and type 2 diabetes: many differences, few similarities. Diabetes 54(Suppl 2):S97-S107

30. Thomas HE, Biden TJ (2009) Bad news for beta-cell apoptosis. Diabetes 58:1725-1727

31. Grunnet LG, Aikin R, Tonnesen MF et al (2009) Proinflammatory cytokines activate the intrinsic apoptotic pathway in beta-cells. Diabetes 58:1807-1815

32. Polzien L, Baljuls A, Rennefahrt UE et al (2009) Identification of novel in vivo phosphorylation sites of the human proapoptotic protein $\mathrm{BAD}$ : pore-forming activity of $\mathrm{BAD}$ is regulated by phosphorylation. J Biol Chem 284:28004-28020

33. Johnson JD, Bernal-Mizrachi E, Alejandro EU et al (2006) Insulin protects islets from apoptosis via Pdx1 and specific changes in the human islet proteome. Proc Natl Acad Sci U S A 103:19575-19580

34. Virdee K, Parone PA, Tolkovsky AM (2000) Phosphorylation of the pro-apoptotic protein BAD on serine 155 , a novel site, contributes to cell survival. Current Biol: CB 10:1151-1154

35. Zhou J, Shao Z, Kerkela R et al (2009) Serine 58 of 14-3-3zeta is a molecular switch regulating ASK1 and oxidant stress-induced cell death. Mol Cell Biol 29:4167-4176

36. Aguilera C, Fernandez-Majada V, Ingles-Esteve J, Rodilla V, Bigas A, Espinosa L (2006) Efficient nuclear export of p65IkappaBalpha complexes requires 14-3-3 proteins. J Cell Sci 119:3695-3704

37. Barthson J, Germano CM, Moore F et al (2011) Cytokines tumor necrosis factor-alpha and interferon-gamma induce pancreatic beta-cell apoptosis through STAT1-mediated Bim protein activation. J Biol Chem 286:39632-39643
38. Gurzov EN, Germano CM, Cunha DA et al (2010) p53 up-regulated modulator of apoptosis (PUMA) activation contributes to pancreatic beta-cell apoptosis induced by proinflammatory cytokines and endoplasmic reticulum stress. J Biol Chem 285:19910-19920

39. Gurzov EN, Ortis F, Cunha DA et al (2009) Signaling by IL-1beta + IFN-gamma and ER stress converge on DP5/Hrk activation: a novel mechanism for pancreatic beta-cell apoptosis. Cell Death Diff 16:1539-1550

40. Wang P, Qiu W, Dudgeon C et al (2009) PUMA is directly activated by NF-kappaB and contributes to TNF-alpha-induced apoptosis. Cell Death Diff 16:1192-1202

41. Quoyer J, Longuet C, Broca C et al (2009) GLP-1 mediates antiapoptotic effect by phosphorylating Bad through a betaarrestin 1-mediated ERK1/2 activation in pancreatic beta-cells. J Biol Chem 285:1989-2002

42. Gardino AK, Smerdon SJ, Yaffe MB (2006) Structural determinants of 14-3-3 binding specificities and regulation of subcellular localization of 14-3-3-ligand complexes: a comparison of the Xray crystal structures of all human 14-3-3 isoforms. Semin Canc Biol 16:173-182

43. Ewing RM, Chu P, Elisma F et al (2007) Large-scale mapping of human protein-protein interactions by mass spectrometry. Mol Syst Biol 3:89

44. Zha J, Harada H, Yang E, Jockel J, Korsmeyer SJ (1996) Serine phosphorylation of death agonist BAD in response to survival factor results in binding to 14-3-3 not BCL-X(L). Cell 87:619-628

45. Pozuelo-Rubio M (2010) Proteomic and biochemical analysis of 14-3-3-binding proteins during C2-ceramide-induced apoptosis. FEBS J 277:3321-3342

46. Luciani DS, White SA, Widenmaier SB et al (2012) Bcl-2 and Bcl$\mathrm{xL}$ suppress glucose signaling in pancreatic beta-cells. Diabetes. doi: $10.2337 / \mathrm{db} 11-1464$

47. Danial NN, Walensky LD, Zhang CY et al (2008) Dual role of proapoptotic BAD in insulin secretion and beta cell survival. Nat Med 14:144-153

48. Zhao J, Meyerkord CL, Du Y, Khuri FR, Fu H (2011) 14-3-3 proteins as potential therapeutic targets. Semin Cell Dev Biol $22: 705-712$ 